\title{
OhioLINK
}

Connecting Libraries, Learning \& Discovery

An $\mathrm{OH} \cdot \mathrm{TECH}$ Consortium Member

ISSUE BRIEF

\section{It's Not What Libraries Hold; It's Who Libraries Serve Seeking a User-Centered Future for Academic Libraries}

January 23, 2020

Gwen Evans,

Executive Director, OhioLINK

gwen@ohiolink.edu

Roger C. Schonfeld

Director, Libraries, Scholarly Communication, and Museums Ithaka S+R

roger.schonfeld@ithaka.org 


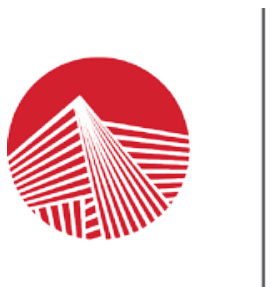

\section{OhioLINK}

Connecting Libraries, Learning \& Discovery

An $\mathrm{OH} \cdot \mathrm{TECH}$ Consortium Member

Established in 1992, the Ohio Library and Information Network (OhioLINK) is Ohio's statewide academic library consortium serving 117 libraries, 88 institutions of higher education, the State Library of Ohio and more than 800,000 end users. Delivering both IT infrastructure and content negotiation, OhioLINK provides students, researchers, faculty and staff with access to digital research collections rivaling top university libraries in the United States and internationally-at a fraction of the cost. OhioLINK also connects library services, print and digital collections among its member institutions and manages collaborative services, including eTutoring, statewide Affordable Learning textbook initiatives, and Open Educational Resources. A member of the Ohio Technology Consortium of the Ohio Department of Higher Education, OhioLINK creates a competitive advantage for its members and supports student and researcher success in the state of Ohio. Learn more at www.ohiolink.edu.

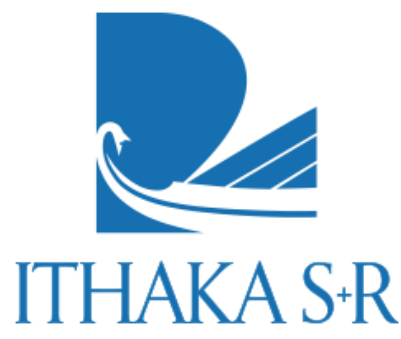

Ithaka S+R provides research and strategic guidance to help the academic and cultural communities serve the public good and navigate economic, demographic, and technological change. Ithaka $\mathrm{S}+\mathrm{R}$ is part of ITHAKA, a not-for-profit organization that works to advance and preserve knowledge and to improve teaching and learning through the use of digital technologies. Artstor, J STOR, and Portico are also part of ITHAKA. 


\section{Table of Contents}

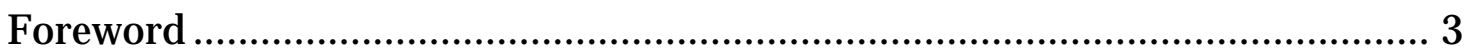

Executive Summary …………........................................................................

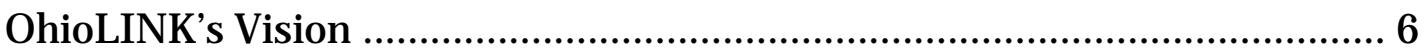

Introduction: The Business of an Academic Library..........................................

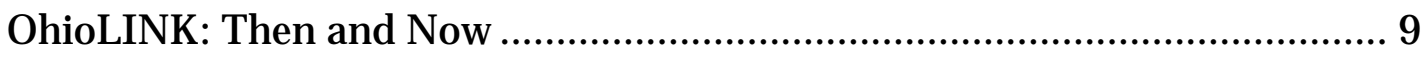

ILS Systems: Enablers or Impediments? ........................................................10

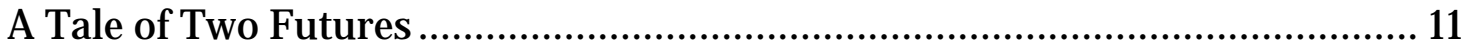

Where Systems Fall Short................................................................................ 13

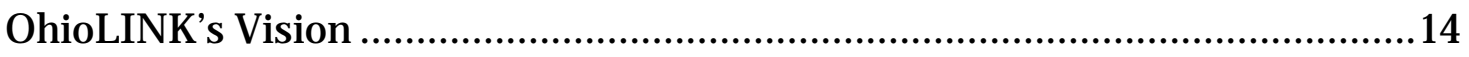

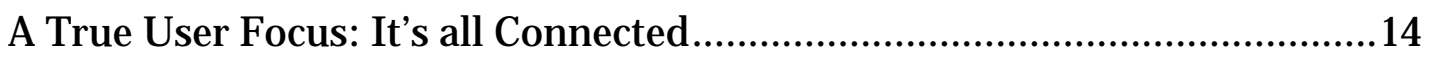

A Facilitated Collection ............................................................................18

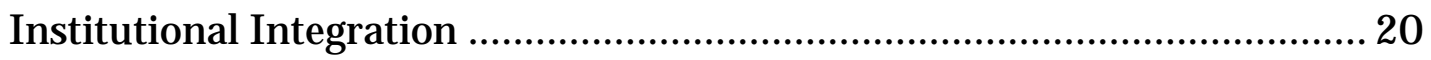

Integrated Business Intelligence.................................................................21

Looking Ahead: New Futures, New Systems.................................................. 23

History and Timeline for ILS Visioning ........................................................... 24

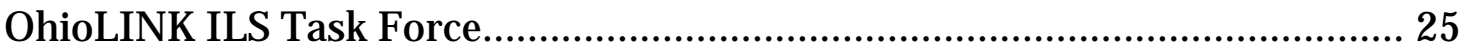




\section{Foreword}

The mission of academic and research libraries is expanding, and our work is transforming. Collections alone are no longer sufficient to articulate our new value proposition and establish ROI to our institutions. Our academic and research libraries are doing more than just managing collection-centric resources, we are contributing to faculty productivities and student success. As we aim to support the goals of our colleges and universities and maintain mission relevance, including technological advancement, we must also understand and support the evolving needs and requirements of our users.

As chair of OhioLINK's Transforming the Integrated Library Systems (ILS) working group, it has been my pleasure to lead a process designed to examine our needs for such a transformed systems environment. My fellow members-representing a wide array of institution types, from community colleges to research universities and both public and private institutions-included Katie Blocksidge, Kenneth Burhanna, Beau Case, J erome Conley, Alyssa Darden, Mary Hamburger, Ken Hirsch, Michelle Kraft, and Kathy Webb. We were supported by Gwen Evans, Amy Pawlowski, and Theda Schwing from OhioLINK. I also want to recognize contributions from several colleagues from Ithaka $\mathrm{S}+\mathrm{R}$, including our leading consultant Roger Schonfeld, as well as project team members Jane Radecki and Joseph Esposito. Our work began in 2018 and is being published into a market that is more consolidated than ever.

Within the OhioLINK consortium, most of our members have shifted their primary focus from print collections to digital-enabled operations as the library continues its digital transformation. In parallel, our libraries are focused increasingly on advanced initiatives to foster student success and support the research enterprise- this is our future. The systems needed to enable this work require a transformation just as complete.

Ultimately, our recommendations are clear. We are looking for a new kind of library system (or systems) —one that definitively places the user at the forefront, one that largely amplifies our evolving new library mission, and one that seamlessly works in concert with other systems in the academic enterprise digital ecosystems. We appreciate the radical nature of what we are seeking, and we expect it will likely require the creation of an entirely new technical architecture for the next generation of library systems. It is our belief that nothing less than this is needed in order to enable libraries to meet their expanded missions in a changing environment.

As we witness continued consolidation in the commercial ILS market, it is our hope that existing providers and open source initiatives will be prepared to make the investments necessary to achieve our vision. We also recognize that new providers may be interested 
in joining this market at a moment that potentially requires a major investment, with great potential. My colleagues and I at OhioLINK look forward to continuing as leaders in the library space and working in partnership with providers and initiatives that are interested in providing the systems necessary to support our vision.

\section{Xuemao Wang}

Past Chair, OhioLINK Library Advisory Council Coordinating Committee (LACCC)

Vice Provost of Digital Scholarship

Dean and University Librarian

University of Cincinnati 


\section{Executive Summary}

In 2018, OhioLINK engaged its membership to envision a constellation of platforms and applications that would take the next step beyond "next-generation" commercial integrated library systems (ILS). This paper is the result of that process.

The business of higher education, as it relates to libraries, is amid continued and drastic change. Managing collections is now but one aspect of library management. Libraries support teaching, affordable learning, and innovative research. They are managing services and products, online and off, amid expanding service offerings and technological advancements while under added pressure to reduce costs and barriers for people who want to learn-be it for a certificate, a two- or four-year degree, or a Ph.D.

The responsibilities of academic libraries have evolved, yet Integrated Library Systems (ILS) still narrowly focus on the acquisition, management, and delivery of objects while the end user remains in the background. It is OhioLINK's belief it is imperative to shift that focus, moving from collections and holdings ${ }^{1}$ to those that use them. It's not what libraries hold, but who libraries serve.

OhioLINK's membership encompasses 117 higher education libraries with a range of institution types and a total headcount of more than 800,000. Its membership consists of 16 public university libraries, 48 independent college libraries, 23 two-year college libraries, 16 regional campus libraries, eight law school libraries, five medical school libraries, and the State Library of Ohio. The sheer diversity of the collection of libraries that comprise this consortium makes OhioLINK a microcosm of the nation's academic libraries in higher education. Its importance and influence in the higher education market is well-established, and its needs have outpaced existing industry offerings.

To this end, this paper does not serve as an indictment, but an invitation to collaborate: OhioLINK members are issuing this white paper to assert that the systems it buys and invests in will require a fundamental re-orientation to the needs of the academic user, and similarly a fundamental re-architecture and re-configuring to meet the changing business requirements of institutions. This paper serves to articulate those needs in greater detail, as well as their current availability or unavailability in the marketplace. This white paper is not about a systems migration, or a critique of OhioLINK's current ILS. While its membership is not initiating immediate change, it is making a clear statement that systems that support the return on investment of higher education institutions and provide great value to the range of their users, from students to world-

${ }^{1}$ Materials owned by a library system. 
class researchers, are imperative in enabling libraries to meet their respective missions and goals.

Now is the time to invest in creating a new type of library system that is fundamentally centered on the user, enables libraries to create a facilitated collection, integrates with the higher education institution, and provides rich analytics and intelligence.

OhioLINK has a long history of envisioning and executing systems for managing library collections and services. These include the collaboration with Innovative, Inc. in the early 1990s that resulted in easy-to-use, user-initiated interlibrary loan as a foundational service, and peer-to-peer lending across library consortia. OhioLINK has also created multi-publisher digital journal and e-book platforms, as well as a multi-tenant statewide open access digital theses and dissertation platform. ${ }^{2}$

\section{OhioLINK's Vision}

- Libraries are reorganizing themselves to center on the user. Yet, every library system in existence today is centered around the collection of a given library. This is entirely incompatible with libraries' strategic direction. Systems, like the libraries to which they provide services, must be completely re-architected to center on the user.

- Today's libraries are responsible for facilitating access to collections in a multitude of formats, through collecting, licensing, open access models, and an array of crossinstitutional collaborations-yet library systems remain overly centered around the tangible collections of individual institutions. Systems must be completely re-architected to enable the facilitated collection.

- The library is increasingly integrated into any number of research, teaching, and learning processes within a higher education institution. But, other than for basic business processes, its systems tend to remain all too siloed. Library systems must be completely re-architected to integrate effectively on a service and data layer with other systems that enable research, teaching, and learning.

- In most sectors, digital tools have enabled the provision of vastly improved business intelligence. Modern business intelligence should enable libraries to analyze, improve, and communicate their value, optimize their operations, and strengthen their negotiating position. Library systems must be completely re-architected to provide modern business intelligence capabilities for individual libraries as well as their consortia.

2 Halle Mares, "OhioLINK's 25th Anniversary: A Concise History 1992-2017," OhioLINK, https://www.ohiolink.edu/sites/ohiolink.edu/files/uploads/25th\%20Anniversary\%20History\%20Booklet.pdf. 


\section{Introduction: The Business of an Academic Library}

The business of an academic library is to support the educational and research mission of its parent institution. Exactly how academic libraries fulfill that function has changed dramatically. Academic libraries must align their services and content to function as a higher education business, while simultaneously serving the evolving needs of its users, or risk irrelevance - as in the well-known example of 19th century railroads' failure to recognize they were in the transportation business, not the railroad business.

For the most part, the major system tools for managing content have been designed for, and remain focused on, managing print. Print - the way it is acquired, the metadata that accompanies it, the metadata that is attached to it within the library, its provision, access, storage, and preservation -is but a small part of the knowledge that the library now collects, organizes, preserves, and makes accessible. The "Integrated Library System" or ILS, ${ }^{3}$ fails to adequately manage increasingly complex and increasingly digital information environments. Furthermore, even the current offerings fail to manage print adequately in the changing environment. What libraries need to know about print today is vastly different than what we needed to know about print two decades ago. It is our contention that even so-called "next-generation systems" are insufficient to supply both the needs of our users and the needs of our institutions.

${ }^{3}$ We use the term ILS throughout the report in its broad sense, to encompass those systems that are marketed as a "Library Services Platform" or LSP. 
Fig 1. The Primacy of Print is Past

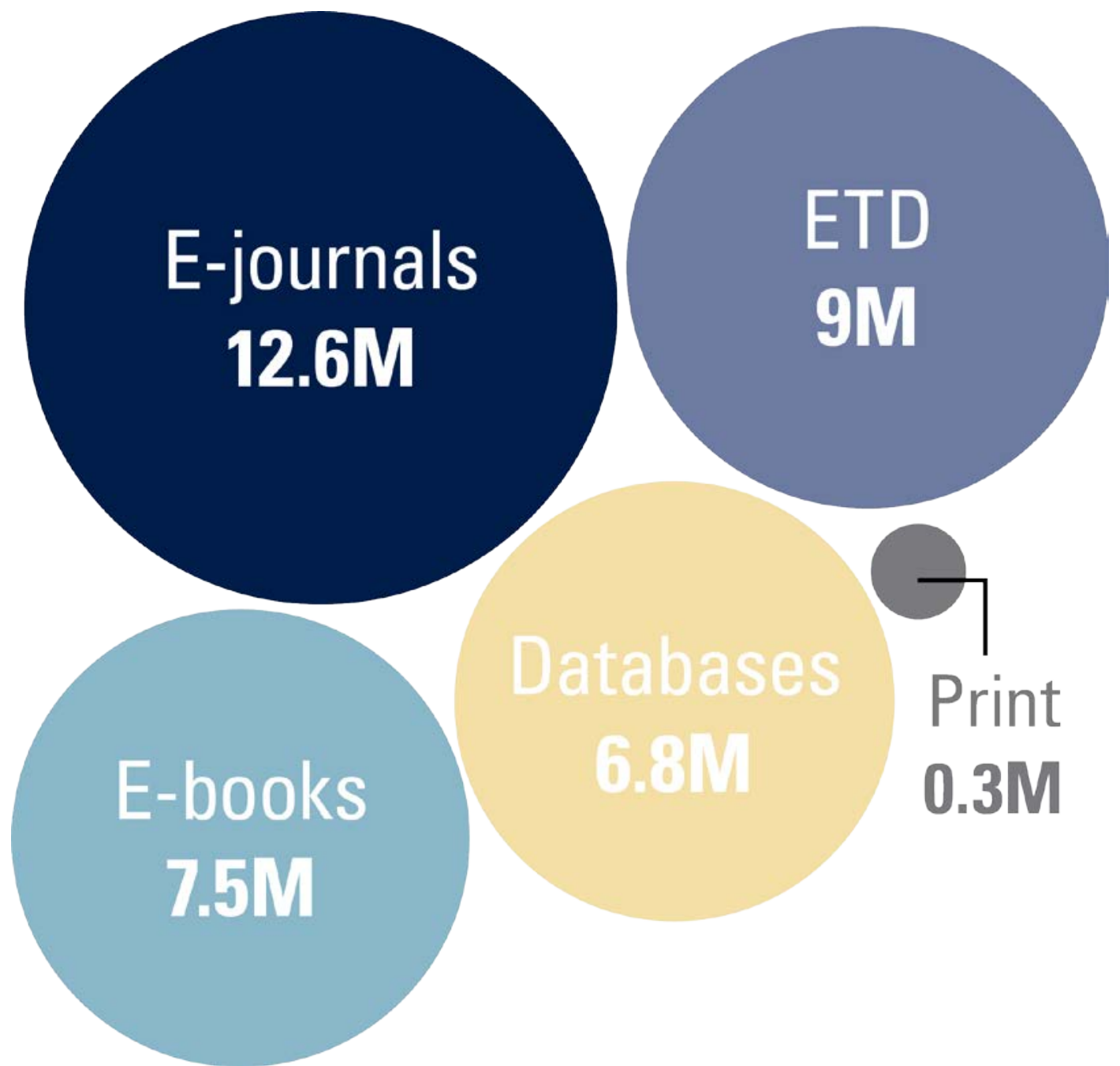

Snapshot of scale of print use versus digital: 2018 consortial activity across OhioLINK. E-theses and Dissertations statistics are global downloads from OhioLINK's Open Access ETD center containing over 100,000 dissertations and theses from 34 Ohio institutions. E-journals, E-books, and Databases downloads are from resources provided by the consortium and available to all members. Print borrowing refers to print resource lending between members.

The striking difference from the environment of the past is that while the library still physically occupies a central position on campus, most of user activity takes place in a highly decentralized virtual environment that library facilities, staff, and applications no longer control or channel. This requires a fundamental shift in how libraries handle their business. The older model is an "outside in" model of user access and acquisition, where both users and materials come to a centrally managed location, are organized or directed, have their access mediated, and the items redistributed. Users and materials now must increasingly be managed in an "inside out" model, where the user and their modes of access (computer, mobile device, the applications on them, and cloud services) 
are at the center - and users reach for materials (or metadata about materials) that are assembled and delivered on an ad hoc basis to the user at the center. ${ }^{4}$

To this end, the members of OhioLINK are issuing this white paper to assert that the systems we buy and in which we invest will require a fundamental re-orientation to the needs of the academic user, and similarly a fundamental re-architecture and reconfiguring to meet the changed business requirements of the institution. This paper serves to evaluate those needs in greater detail, as well as their current availability or unavailability in the marketplace.

\section{OhioLINK: Then and Now}

OhioLINK is a unique consortium with a rich history. OhioLINK began in the early 1990s as the result of an initiative by the Ohio Department of Higher Education's Board of Regents to address an increasing shortage of physical space in libraries and the creation of a statewide electronic cataloging system. Since then, the consortium has grown and it has expanded its services considerably, with a mission to facilitate cost-effective acquisitions, information sharing, preservation of both its print and electronic resources, and student success initiatives, including collaborative tutoring services and affordable textbooks.

On average, most consortia in the United States are comprised of more than 40 member libraries and serve multiple types of libraries. ${ }^{5}$ OhioLINK is comprised solely of academic institutions of higher education and serves 117 full members ${ }^{6}$ who have a wide range in institution type, and a total headcount of more than 800,000. The membership consists of 16 public university libraries, 48 independent college libraries, 23 two-year college libraries, 16 regional campus libraries, eight law school libraries, five medical school libraries and the State Library of Ohio. ${ }^{7}$

On behalf of its member libraries, OhioLINK maintains an "extensive digital library of ebooks, e-journals, databases and audiovisual materials." ${ }^{3}$ Students, researchers, faculty and staff have access to this wealth of scholarly resources through a number of

\footnotetext{
${ }^{4}$ Lorcan Dempsey, "Outside-In and Inside-Out Redux," Lorcan Dempsey's Weblog, 6 June 2010, http://orweblog.oclc.org/outside-inand-inside-out-redux. I

5 OCLC, "A Snapshot of Priorities \& Perspectives: U.S. Library Consortia," Survey Report, 2013, https://www.oclc.org/content/dam/oclc/reports/us-consortia/214986-member-communication-survey-report-consortia-review.pdf.

6 Ohio Department of Higher Education, "About OhioLINK," OhioLINK, 2019, https://www.ohiolink.edu/content/about ohiolink. ${ }^{7}$ Ibid.

${ }^{8}$ Halle Mares, "OhioLINK's 25th Anniversary: A Concise History 1992-2017," OhioLINK, https://www.ohiolink.edu/sites/ohiolink.edu/files/uploads/25th\%20Anniversary\%20History\%20Booklet.pdf.
} 
platforms, including more than 46 million print books that are accessible through the central catalog and shared via courier service; 24 million articles in 10,000 journals through the Electronic J ournal Center (EJ C); 100,000 e-books through the Electronic Books Center (EBC); and tens of thousands of other resources available through OhioLINK and its member libraries.

OhioLINK plays an important role for its members in negotiating and licensing access to these content resources, and it provides an array of ancillary services, including providing for the delivery of tangible collections shared among its members. OhioLINK licenses some components of library systems for its members as a group, and it also utilizes library systems for its own work. Its perspective is therefore informed by its breadth and scale - a combination of its individual member needs as well as its centralized and coordination efforts on behalf of its members.

Underpinning the management of many scholarly resources is an integrated library system (ILS), currently provided to OhioLINK members by Innovative Interfaces, Inc. ("Innovative"). Such library systems are used to manage libraries' acquisitions, cataloging, discovery, ${ }^{9}$ and circulation, and the underlying data are crucial for analyses that drive business decisions. With the growing movement toward digital content and the need to better integrate with a variety of systems that enable research, teaching, and learning, OhioLINK has begun to consider its needs for an ILS or other ILS-adjacent services that would better fit member needs.

\section{ILS Systems: Enablers or Impediments?}

Academic and research libraries' strategic direction is aligned with that of their parent institutions, in support of student success, research excellence, and broad community engagement-and thus they must be able to manage the library in the context of the university.

The library systems marketplace has not kept pace with these needs. Over the past decade, there has been a major shift in the marketplace, with two vendors developing competitive offerings among the cloud-based multi-tenant systems, which reduce local hosting costs and enable cross-institutional collaboration. Notwithstanding investment in several open source ILS initiatives, the search for alternative business models in the ILS marketplace has been prioritized over the emerging strategic directions that these systems must enable, and they have not achieved widespread adoption among academic and research libraries. There are fewer meaningful competitors in the systems

${ }^{9} \mathrm{~A}$ search tool that allow library users to find holdings. 
marketplace than there were a decade ago, and it is not clear that the "next-generation" systems even meet the full array of current needs. ${ }^{10}$

As new strategic directions have emerged, the management of library collections will continue to become a smaller share of library activity. Many library leaders, out of frustration with the limitations of the incumbents, have sought to limit their spending and strategic engagement. They have come to accept low expectations for their library systems.

OhioLINK has taken a different approach. As OhioLINK and its members implement innovative partnerships and new service models, an added shift has been signaled: the centering of their services portfolio on their users rather than on their collections. Recognizing the limitations of current offerings in meeting this shift, OhioLINK examined its business requirements and those of its members for systems today, concluding that the current incumbents do not offer a system that will meet future needs. Wanting to explore the possibilities, OhioLINK engaged in a planning exercise to develop a vision for a new system that would address libraries' strategic directions as they focus on users more so than collections. It is a vision that will enable systems planning rather than a vision for the services that OhioLINK or its member libraries will offer.

\section{A Tale of Two Futures}

To illustrate the user-centered vision that we develop at greater length below, imagine two futures where using the library is a pleasurable and seamless experience, for a student and a researcher, as well as for the library itself.

An undergraduate student, who is currently a high school student in Columbus, Ohio, enrolled simultaneously in Ohio's College Credit Plus program, is taking college classes at Miami University of Ohio to begin their study toward a bachelor's degree. In completing a paper on the economics of higher education, this student is conducting research during Spring Break from their parents' home, where off-campus access is entirely seamless, without the annoyance of a proxy server or the need to follow any particular workflow in order to access needed materials. In recent weeks, this student has been conducting a variety of online searches. And, since this user has opted in to a feed-based service, they also receive periodic individualized updates about materials that may be of interest to them, directly inside of their course management system. Some materials are consumed digitally, but when the student wants a print copy of a monograph they have been reading digitally, it is available to order and is delivered with

${ }^{10}$ See American Libraries' 2019 Library Systems report for more details about the marketplace. 
tracking to the nearest location of the student's choosing, in the same seamless manner without resource and workflow silos. Regardless of where and how discovery takes place, the student is provided with ready access to the best available copy of the item, in tangible or digital form-recognizing their entitlements ${ }^{11}$ from across their public library, alma mater, current institution, and other institutional affiliations.

A medical researcher at the University of Cincinnati is collaborating with a colleague at Case Western Reserve University (both in OhioLINK) and with a third colleague at Oxford University, funded by a grant from the NIH. They are able to set up access and journal alerts for their joint work in three labs with multiple potential authors by seamlessly merging their respective e-resource entitlements and are able to integrate library materials and citations, their own data, and their draft publications in a common online working platform. When lab members are ready to publish, they are able to track where articles have been submitted, accepted, and where and how the Open Access provisions required by the NIH have been satisfied. The library maps seamlessly to the researchers' workflows.

Administratively, the library can be readily managed as part of the university and in its consortial context. The library has access to anonymized aggregate data about the use of materials in the class that the student is taking, and is able to show their administration that students who use library materials receive higher grades and are more likely to graduate on time. When students are evaluating the costs of textbooks as they register for classes, e-books licensed by the library are automatically presented in the registration system as the optimal choice, or are presented to the faculty as they enter their textbook orders to the bookstore, and cost savings to students provided by the library and the ROI on library materials are automatically calculated based on enrollment and market price of the current text. Each of the member libraries of OhioLINK, for example The Ohio State University, is able to manage its complex multi-format collection as a vital part not only of the statewide facilitated collection but also in the context of its commitments to the Big Ten Academic Alliance; many OhioLINK members are also members of the Center for Research Libraries, HathiTrust, NELLCO Law Library Consortium, etc. Librarians analyze business information that is well organized, enabling them to make evidence-informed decisions about how best to manage their collections and serve their users. The consortium has ready access to the data needed to support its negotiating position for a transformative license agreement with a major publisher and, once that agreement is signed, has the tools to manage the flow of monies to support not only access to content but also open access publishing services. OhioLINK can forecast and align consortial library resource needs by mapping state data on curriculum and enrollment trends to evaluation of renewals and new purchases. Resources are steadily

${ }^{11}$ Access privileges. 
reallocated away from services and collections whose usage and value has declined, and towards those that directly support student success and research excellence. The capabilities would make it possible to manage the modern library.

Systems and platforms should make the library readily manageable and a pleasure for its users.

\section{Where Systems Fall Short}

At the most basic level, OhioLINK believes that current systems are inadequate to meet current business requirements for managing library collections and their use. While systems have improved dramatically in the transition to cloud-based multi-tenant platforms, they have not kept pace with the needs of individual libraries nor their efforts to collaborate in a consortial context.

Data are at the heart of managing the modern library, but a lack of standards and a profusion of siloed platforms create enormous challenges. Platforms should support access to, and utilization of, live data, not only for the library systems platform of the library of a single institution but in connection with other library systems and other institutions within a collaboration. Platforms should enable business metadata (including information about costs, terms, and rights) to be utilized, shared, and analyzed effectively, without being unduly tied to and bound by the limitations of standard library descriptive metadata. These foundational gaps create enormous challenges for the single library alone, even more so to efforts to collaborate to improve offerings and reduce collective costs.

The modern library is digital first and so should be its platforms. Licensed e-resources constitute the dominant usage of the library, and platforms should enable these licenses and collections to be readily managed both at an institutional and consortial level, including as they shift to incorporate various kinds of open access services. Discovery of and access to these electronic resources should be readily integrated into user workflows. No platform is adequate if it does not provide a first-rate solution to e-resources.

Tangible collections such as print books for long-form reading and special collections remain important-and platforms should not be an impediment to their continuing relevance. Libraries should be able to manage their tangible collections with greater efficiency, which over time will increasingly include models for sharing acquisitions, shared governance and preservation of common collections, and floating collections. ${ }^{12}$

12 Items that move among library locations based on use, rather than being housed at a specific location.

IT'S NOT WHAT LIBRARIES HOLD; IT'S WHO LIBRARIES SERVE: SEEKING A USER-CENTERED FUTURE FOR ACADEMIC LIBRARIES 13 
While many libraries may not require all these features today, systems should support pilots and experimentation rather than serve as obstacles.

Providers may think they are delivering on some of these requirements, and indeed some are available via add-ons and workarounds, but these cause their own challenges. The core business requirements listed in this section are among those that must be delivered in order for libraries to achieve their current goals for the management and use of library collections.

\section{OhioLINK's Vision}

Today, many academic libraries have already moved far beyond the management and use of collections as their core responsibilities. Libraries are developing advanced services and partnerships in support of student success and research excellence. They are driving efficiencies into their print collections as they manage a digital transformation. And they are working in a competitive marketplace for information, in which consumer resources like Google, Facebook, Uber, and Amazon define user expectations, while fake news runs rampant and users need vetted resources and clear signals of trust and authority. Beyond today's core business requirements, OhioLINK has identified four areas of strategic importance are at the heart of the library system of tomorrow:

1. User focus

2. Facilitated collections

3. Institutional integration

4. Integrated business intelligence

\section{A True User Focus: It's all Connected}

Libraries are reorganizing themselves to focus on the user. Yet, every integrated library system in existence today is centered around the collection of a given library. This is entirely incompatible with libraries' strategic direction. Systems, too, must be completely re-architected to center on the user.

\section{Definition}

The academic user is interested in discovering and accessing an array of publications and primary sources, not just those at their local institution. For the user, discovery and 
access is typically embedded as part of a larger research, teaching, or learning workflow and no longer has the library as the primary physical or virtual starting point. ${ }^{13}$

Fig. 2 The library is not where our users start

\section{Sessions}

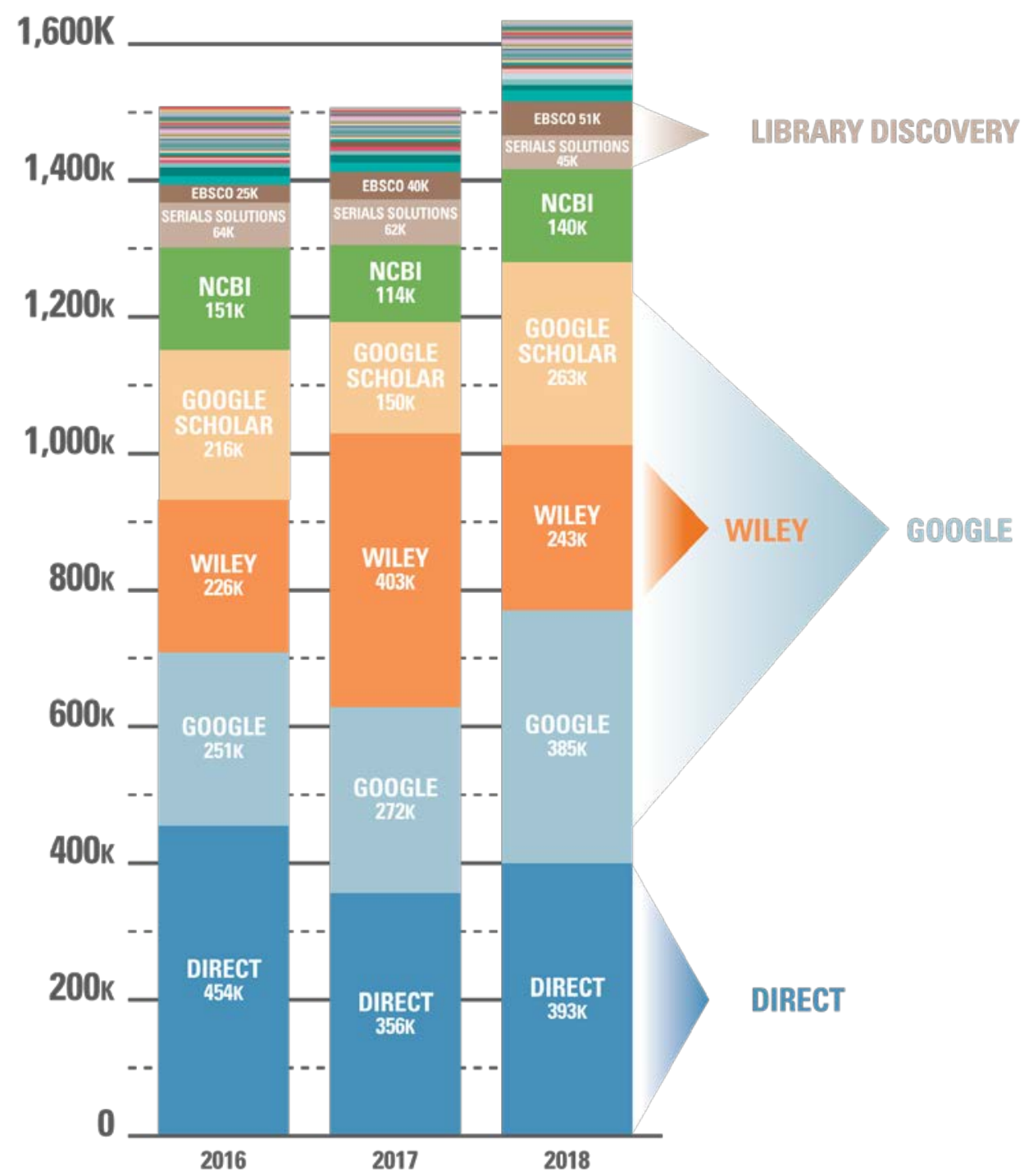

OhioLINK user routes to all Wiley Content 2016-2018. Google and Google Scholar are by far the greatest source of access sessions for OhioLINK users. Almost all our 117libraries have implemented either EBSCO Discovery Service or Summon as discovery layers.

13 Ohio Department of Higher Education, "Summit," OhioLINK, 2019, https://www.ohiolink.edu/sites/default/files/2019\%20Summit\%20Magazine.pdf. 
User expectations of finding, accessing, tracking, and using content and services are increasingly driven by consumer technology product experiences that have dramatically re-centered on the user, for example Amazon Prime memberships and delivery, streaming media, Uber, consumer-facing real-time inventory and location systems used by Ikea and Lowes, and password management apps integrated seamlessly into smartphones. Academic users increasingly have multiple overlapping institutional affiliations across not just national, but global spheres. Addressing these core characteristics is essential to centering on the user rather than the collection.

\section{Current Limitations and Problems}

A user-centered approach must also address current limitations and problems in today's library systems. ${ }^{14}$

Systems remain centered around an essential set of collections management functionalities, including acquisitions, e-resources, and circulation, among others. These management functionalities have been conceived to be primary or exclusively local to one campus/ library or institutional system. These systems also privilege the management of print when user activity related to discovery and access of content is overwhelmingly digital. This print-centric, local, library-bound orientation assumes the library as the most important starting point, when users require that library resources are integrated easily into a much wider information pool that can include open access content, internet content, individual subscriptions, and multiple institutional and organizational affiliations that may offer expanded and specialized resources. While the discovery systems initiatives of the past decade have markedly improved the possibility of discovery beyond institutional holdings, especially with respect to e-resources, they have yet to provide a collection-agnostic approach to discovery that is truly centered only on user needs.

Today's library systems tend to treat the user behaviors of discovery and access as largely disconnected from other research, teaching, and learning workflows. To be sure, some workarounds have been developed. But it often remains challenging to bring discovery and access into the environments where users need them. To take two examples: Lab research groups have extensive needs for team-based current research awareness, which is poorly supported by library-provided discovery and access. And, course management systems and other kinds of instructional and learning platforms are increasingly important to residential education and absolutely essential to distance learning, yet integrating discovery and access into these course-based workflows is all too difficult.

${ }^{14}$ Roger Schonfeld, PowerPoint Presentation, OhioLINK Member Summit, May 2019. 
Finally, many users have multiple institutional affiliations. They may have access rights based on a local public library, their alma mater, and their current institution, to take three examples. But users find it almost impossible to take advantage of the full array of their access entitlements given the institutional nature of access management and its different implementations on campuses or within organizations. In addition, many users have more granular entitlements or services, such as departmental or individual subscriptions, digital books, courseware, etc., that are used side-by-side with library resources.

\section{Vision}

User centeredness is our number one priority. It includes the following necessary elements:

- A system designed specifically to be centered around the users' experience and needs rather than collections or inventories.

- A system that allows effective use of library materials embedded within the applications or systems commonly used on campuses or in research, which include course management systems, registration systems showing syllabi and textbook assignments and costs, collaborative work-sharing platforms such as OneDrive and Dropbox, etc.

- Data generated by use of resources is transparent to the user with robust mechanisms for privacy and informed consent of any personalized data sharing to the institution or third parties.

- Access and delivery that are equally effective regardless of a user's starting point, that brings users to the needed/ desired item in a way that is seamless, aware of entitlements, and if necessary shows the cost and time implications for instantaneous delivery or ownership of said material.

- A system that provides signs of trust and authority, for example emphasizing vetted/ reputable/ accurate/ authentic information resources, the version of record ${ }^{15}$, etc.

- Discovery experiences that are differentiated and to some degree mediated by user type and/ or entry point and have the ability to be optionally personalized. This includes intuitive information about other services that may be sought by the user.

- A discovery system that presents all print and electronic options to the user in a way that enables the user to make appropriate guided decisions based on content availability, cost, lag time, format, and so on.

- Content consumption experiences that are appropriate to the material medium and the device - i.e. desktop computer, laptop, mobile device, tablet, and so on—of the users' choice.

15 The final, published version of a journal article, for example. 


\section{A Facilitated Collection}

Libraries' collections roles have expanded far beyond building local tangible collections. Today's libraries are responsible for facilitating access to collections in a multitude of formats, through collecting, licensing, open access models, and an array of crossinstitutional collaborations. Yet library systems remain overly centered around the tangible collections of individual institutions, rather than embracing the full array of practices that libraries have come to embrace. Systems must be completely rearchitected to enable the facilitated collection.

\section{Definition}

A facilitated collection is "a coordinated mix of local, external, and collaborative services assembled around user needs." ${ }^{16}$ For our purposes, the facilitated collection also implies that a group of libraries are choosing to shape its collection together as a group rather than simply accepting the aggregation of its separate collecting decisions.

\section{Current Limitations and Problems}

The current generation of library systems is largely centered around the collections of individual institutions, rather than the sharing environments in which they increasingly wish to be embedded. This entails real challenges for a group of institutions wishing to collaborate towards creating a single facilitated or shared collection, as is the vision of the Big $10 .{ }^{17}$ The answer is not simply to create a cross-institutional systems environment, since most institutions are part of multiple sharing networks, open access agreements, and even collection facilitation initiatives. Rather, systems should reflect and enable the institutionally complex networks on which libraries actually wish to rely. Looking ahead, we can expect to see an increasing number of collaborations that are less centrally organized and less human-curated but rather rely on decentralized or computation-driven modes of facilitation. And, new modes of collection usage will continue to rise, including text and data mining services and other artificial intelligence/ machine learning techniques, which library collections and their systems must enable.

\footnotetext{
${ }^{16}$ Lorcan Dempsey, "The Facilitated Collection," Lorcan Dempsey's Weblog, 31 January 2016, http://orweblog.oclc.org/towards-thefacilitated-collection/.

17 Lorcan Dempsey, Constance Malpas, and Mark Sandler, "Operationalizing the BIG Collective Collection: A Case Study of Consolidation vs Autonomy," OCLC Research, 2019, https://www.oclc.org/research/publications/2019/oclcresearch-operationalizingthe-BIG-collective-collection.html.
} 


\section{Vision}

To drive towards greater efficiency while staying centered on user needs requires the steady development of a more facilitated, more shared model for collecting and collections, one that respects the benefits and disadvantages of each material type and format rather than continuing to center on print as the canonical object of collection. The current systems environment constrains OhioLINK's ability to innovate on collections in a shared environment. Visions of a facilitated collection go well beyond the simple sharing of existing collections. OhioLINK wants its systems environment to enable it to move steadily towards a facilitated collection. This will require the following elements:

- A system that enables managing the kinds of shared, or possibly even unified collections, towards which libraries will wish to move in the coming years. This includes shared acquisitions and/ or unified acquisitions on behalf of member libraries, the management of digital materials, the creation of floating collections, shared dispositions via the last copy, and so on.

- Inventory management and stewardship that is shared across the system and is simultaneously being optimized for different content mediums. This would include unified information on print and digital preservation, for example the ability to know that a print copy with a last-copy designation exists of a digital book that is part of a digital preservation program.

- Increasing opportunities to manage the collections collectively among both dispersed and/ or centralized teams of staff in the areas of technical services, document delivery, systems administration, etc. with the opportunity for individual libraries/ collections to opt in or out of particular services.

- Shared print models, whether through depositories or otherwise, that provide the capacity to enable a more optimized collections management system.

- The ability to readily embed both individual library collections and consortial collections into others' discovery and access ecosystems, including non-library discovery systems, such as textbook availability.

- A greater importance placed on the role of the library and library consortia in brokering access to content.

- Seamless integration of information about and discovery of special collections and other digitized content particular to institutions into the collective collection.

- A recognition of the growing importance of open access content, which needs to be integrated both on the payment side and in terms of discovery.

OhioLINK has specific sharing needs for all of its members. Some of these members also have their own sharing needs that reflect deeper subsets and go well beyond OhioLINK 
members. ${ }^{18}$ Objectives in creating a facilitated collection will be addressed opportunistically over time, but systems should enable the future vision today so that they will not be a barrier to change as they are today.

\section{Institutional Integration}

The library is increasingly integrated into any number of research, teaching, and learning processes within a higher education institution. But, other than for basic business processes, its systems tend to remain all too siloed. Library systems must be completely re-architected to integrate effectively on a service and data layer with other systems that enable research, teaching, and learning.

\section{Definition}

Library systems must be thoroughly linked to, if not integrated with, higher education systems.

\section{Current Limitations and Problems}

The challenges of linking relevant higher education systems, such as finance and directory, with the library are well understood. Today, we can see a growing array of other higher education systems designed to foster student success and support the research enterprise. Current library systems make it challenging or in some cases impossible to bring library resources and expertise in service of research and teaching needs. Library systems providers must see it as a core part of their role and responsibility to design their systems to integrate with those of other providers and to work in partnership with other providers to enable this to occur.

\section{Vision}

At a higher education institution, it should be clear that the library system is a higher education system. OhioLINK wishes to see the following elements of strategic connection and engagement to achieve this:

- The collections and expertise of the academic library are tightly integrated into the course management system and textbook assignment/provision systems;

\footnotetext{
18 See Lorcan Dempsey, Constance Malpas, and Mark Sandler, "Operationalizing the BIG Collective Collection: A Case Study of Consolidation vs Autonomy," OCLC Research, 2019, https://www.oclc.org/research/publications/2019/oclcresearch-operationalizingthe-BIG-collective-collection.html; and B1G Academic Alliance, "Commitment to an Interdependent Future: A Statement by the Big Ten Library Leadership," Big Ten Academic Alliance, September 2019, https://www.btaa.org/docs/default-source/library/the-bigcollection.pdf?sfvrsn=284f49f3 2.
} 
- Library and consortial holdings and entitlements data are easily integrated and analyzed in curriculum and accreditation assessments and dashboards. Library metadata and content are capable of being matched and analyzed alongside other higher education subject, degree and research program designations to allow rapid and machine-capable analysis and assessment. For example, a proposed new curriculum or course in other systems would automatically send an alert to the library and generate an assessment of available and needed library resources to support new programs;

- Research workflow services, including laboratory notebooks, research data deposit/sharing, electronic theses and dissertation management and publication, and preprint deposit/ sharing, are well integrated into the library system;

- Digital records management and preservation integrated with other campus systems;

- Relevant library expertise, entitlements, and systems are integrated with institutional research administration, assessment and expertise discovery products; including the ability to capture and analyze relevant data at system and consortial levels, such as state public higher education systems and groupings;

- Improved integration with institutional identity management;

- Seamless integration of library/ consortial acquisitions system with campus-based purchasing systems

- Library and campus publishing programs, including university press programs reporting to the library and creation of Open Educational Resources (OER) are easily integrated into relevant library and discovery systems both locally and in wider contexts, such as course management systems and OER indexes.

\section{Integrated Business Intelligence}

In most sectors, digital tools have enabled the provision of vastly improved business intelligence. Modern business intelligence should enable libraries to analyze, improve, and communicate their value, optimize their operations, and strengthen their negotiating position. Library systems must be completely re-architected to provide modern business intelligence capabilities for individual libraries as well as their consortia.

\section{Definition}

The ability to connect various library systems offers up new opportunities to provide improved services for both users and the business intelligence necessary to optimize the modern library. 


\section{Current Limitations and Problems}

Today's library systems lack many modern business intelligence capabilities that would benefit a library or consortium. Some of the integrations discussed in the previous section are a prerequisite for many of the business intelligence capabilities, which require real-time data. In addition, data about everything from costs to an expanded definition of usage often remain siloed, resulting in a remarkable absence of the business intelligence necessary to optimize the operations of a modern user-centered library.

\section{Vision}

The library system should enable the kinds of business intelligence that are needed for a sophisticated library and an ambitious consortium to manage their affairs. OhioLINK wishes to envision a new system with expansive analytics and intelligence. To do this the consortium has outlined the following points:

- Fundamentally, the system should collect and provide all data to the library in ways that enable their reuse and reanalysis on and off the platform without additional fee or limitation.

- A system that contains discovery, aocess, and usage data in a way that can be used to optimize inventory.

- A system that analyzes not only usage of the library resource, but the curricular or research impact of that resource. For example, usage data that shows how many undergraduates versus faculty used that resource, and in what classes it was linked through the course management system.

- Customer relationship management (CRM) that is unique and allows the user the ability to view information about themselves, or is specifically tailored for themselves, including data use and privacy policies of library and research resources.

- Full usage and circulation information that is available across multiple formats and libraries for the collective group.

- A system that enables the management and analysis of contractual terms, including interlibrary loan, privacy and data use terms, that is available across multiple formats and libraries for the collective group.

- Real-time data and actionable information passed back and forth between users, library staff, and vendors without resorting to email and ticketing systems.

- New intelligence that provides data for the library to assess their systems and activities to continuously modernize and integrate them to meet not just library needs, but campus needs, more broadly.

Today, none of these above functions are being met by the incumbents nor is there a platform in the systems marketplace that can satisfy these needs. Outdated discovery 
and access paradigms, siloed data and systems platforms that do not meet the essential requirements of a library create multiple challenges for OhioLINK and any consortium. Given the problems faced by a diverse make-up of institutions, a new "user centric paradigm" that creates a truly encompassing integrated system is clearly needed to ensure the furtherment of education, student success and excellence, and the use of the library.

\section{Looking Ahead: New Futures, New Systems}

Today's "next-generation" cloud systems do not meet all of OhioLINK's current needs, let alone its strategic directions. Current systems that are focusing on just collections and organized and designed around the affordances of print will continue to serve as strategic impediments to key calculated transformations, including realignment with the parent institution and its user communities. ${ }^{19}$ Now is the time to invest in creating a new type of library system that is fundamentally centered on the user, enables libraries to create a facilitated collection, integrates with the higher education institution, and provides rich analytics and intelligence.

The current "next-generation" library systems platforms are more "integrated" than even the previous generation of integrated library systems. We make no assumption that greater unification is necessarily beneficial to achieving the vision we have set forth. It could be that the time has come to envision a "dis-integrated" library system-one that makes a cleaner separation between the administrative functions, such as collections management on the one hand, and the user-centered discovery and access experience on the other. If such a direction made sense, it would need to incorporate robust interoperability and perhaps even a common platform architecture.

Whatever its specific architecture, it is imperative that we see a new kind of library system-one centered on the user and not the collection; one enabling collections to be facilitated and not just purchased/licensed; one connected with higher education and not just siloed in the library; and one providing the kinds of strategic integrations and business intelligence necessary to operate the modern library. It is our belief that this fundamental reimagining of library systems will enable academic and research libraries to reestablish the connections between their services and the needs they have to support to promote student success and research excellence.

${ }^{19}$ Constance Malpas, "University Futures, Library Futures: Institutional and Library Directions in OhioLINK," Presentation to the OhioLINK Library Advisory Committee, June 2018, https://www.slideshare.net/malpasc/university-futures-library-futures-institutionaland-library-directions-in-ohiolink-101923087. 


\section{History and Timeline for ILS Visioning}

August 2018 Definition of scope of this project as initial part of strategic planning for OhioLINK under the direction of then-Chair of the Library Advisory Council Dean Xuemao Wang. A team is named to collaborate with Library Advisory Council on this challenge.

November 2018 Engagement of Ithaka S+R as consultants to lead the process.

December 2018 First ILS Task Force meeting. Task Force met throughout 2018-2019, including with special focus group.

March 2019 First report and presentation to Library Deans and Directors, entitled Business Requirements for Next Generation Library Systems: A Consulting Report to OhioLINK.

May 2019 Keynote presentation by Roger Schonfeld of Ithaka S+R, and panel of Task Force participants at OhioLINK's annual Member Summit meeting.

December 2019 Last ILS Task Force meeting.

J anuary 2020 Publication of resulting white paper, "It's Not What Libraries Hold; It's Who Libraries Serve. Seeking a User-Centered Future for Academic Libraries." 


\section{OhioLINK ILS Task Force}

Chair Xuemao Wang

Vice Provost of Digital Scholarship, Dean and University Librarian

University of Cincinnati

Katie Blocksidge

Library Director

The Ohio State University at Newark and Central Ohio Technical College

Kenneth Burhanna

Dean

Kent State University Libraries

Beau Case

Dean

University of Toledo Libraries

J erome Conley

Dean and University Librarian

Miami University

Alyssa Darden

Director, Learning and Library Resources

Franklin University and Urbana University

Mary Rider Hamburger

Assistant Director for Technical Services

Moritz College of Law, The Ohio State University

Kenneth Hirsh

Senior Librarian Emeritus

College of Law, University of Cincinnati

Michelle Kraft

Director, Floyd D. Loop Alumni Library

Cleveland Clinic

Kathleen Webb

Dean, University Libraries

University of Dayton 
Special thanks to members of our focus group for their valuable input and insights.

Kelly M. Broughton

Assistant Dean for Research and Education, University Libraries, and

Director of Non-academic Operations \& Strategies, Finance \&Administration

Ohio University

Sue Polanka

University Librarian

Wright State University Libraries

J ennifer Vinopal

Associate Dean for Distinctive Collections and Digital Programs

The Ohio State University Libraries

Alexia Hudson-Ward

Azariah Smith Root Director of Libraries

Oberlin College and Conservatory

Paul Heyde

Team Leader, Acquisitions \& Metadata Services, Kelvin Smith Library

Case Western Reserve University

Brad Warren

Associate Dean of Library Services

University of Cincinnati Libraries

OhioLINK Task Force Members

Gwen Evans, Executive Director

Amy Pawlowski, Deputy Director

Theda Schwing, Manager, Catalogs and Technical Implementation 